eancer is attributable to exposure to carcinogenic agents in the environment and therefore potentially preventable. Potent carcinogens tend to reveal their activity sooner or later, even if no careful investigation is made. The real difficulty relates to weaker agents, none of which by themselves has a maked effect on cancer incidence, but which, together, may very materially increase the cancer burden. R. G. LUCKCOCK

${ }^{1}$ Magee, P. N., and Barnes, J. M., Brit. J. Cancer, 10, 114 (1956).

${ }^{2}$ Magee, P. N., and Barnes, J. M., J. Path. Bact., 84, 19 (1962).

${ }^{3}$ Schoental, R., Nature, 188, 420 (1960).

- Druckrey, H., Preussmann, R., Schmähl, D., and Müller, M., Naturwissenschaften, 48, 134 (1961).

- Magee, P. N., and Schoental, R., Brit. Med. Bull., 20, 102 (1964). - Druckrey, H., Schmähl, D., and Schildbach, A., Naturwissenschaften, 48, 56
'Druckrey, H., and Schmähl, D., Naturwissenschaften, 49, 217 (1962).

${ }^{8}$ Barnes, J. M., and Magee, P. N., Brit. J. Indust. Med., 11, 167 (1954)

${ }^{9}$ Terracini, B., and Magee, P. N., Nature, 202, 502 (1964).

${ }^{10}$ Magee, P. N., Biochem. J., B4, 676 (1956).

${ }^{11}$ Dutton, A. H., and Heath, D. F., Nature, 178, 644 (1956).

${ }^{12}$ Heath, D. F., Biochem. J., 85, 72 (1962).

${ }^{13}$ Magee, P. N., and Vandekar, M., Biochem. J., 70, 600 (1958).

${ }_{14}$ Brouwers, J. A. J., and Emmelot, P., Exp. Cell. Res., 19, 467 (1960).

${ }^{15}$ Magee, P. N., and Hultin, T., Biochem. J., 83, 106 (1962).

${ }^{16}$ Magee, P. N., and Farber, E., Biochem. J., 83, 114 (1962).

${ }^{17}$ Craddock, V. M., and Magee, P. N., Biochem. J., 89, 32 (1963).

${ }^{18}$ Case, R. A. M., Hosker, Marjorie E., McDonald, Drever B., and Pearson, Joan T., Brit. J. Indust. Med.,11, 75 (1954).

${ }^{19}$ Case, R. A. M., and Hosker, Marjorie E., Brit. J. Prev. Soc. Med., 8, 39 (1954).

${ }^{20}$ Lancet, i, 306, 328 (1965).

${ }^{21}$ Davies, Joan M., Lancet, ii, 143 (1965).

${ }^{22}$ Roe, F. J. C., Clin. Pharmacol. Therap. (in the press).

\title{
RECENT ADVANCES IN THE MICRO-IRRADIATION OF CELLS
}

$\mathrm{R}$ ESEARCH workers who are interested in the effects of microbeams of radiation of a variety of biological materials met recently to discuss problems which are currently important in the development of this subject. The meeting was arranged by Dr. M. Bessis and was held in the Laboratoire de Pathologie Cellulaire, le Kremlin. Bicêtre, Paris.

Dr. C. L. Smith (Cambridge) was chairman for the first session, which was concerned with recent advances in the design and construction of microbeams and opened with some comments by H. Glubrecht (Hannover) on the development of an ultra-violet microbeam coupled with an ultra-violet microspectrophotometer of the Caspersson type. He emphasized that the dose of ultra-violet radia. tion which was used for microspectrophotometric measurements on living cells should be not more than onethousandth of that which had been used in the microbeam to irradiate the cells. In answer to L. Trapp (Zeiss, Oberkochen) he said that ultra-violet absorption measurements had been made over areas varying from $0.7 \mu$ to $12 \mu$ and dose-rates had been obtained by taking into consideration the reflexion and transmission coeffieients of all the rolevant surfaces. G. Nomarski (Paris) indicated the importance of increasing the ultra-violet reflecting power of aluminized mirrors above the normal figure of 85 per cent, particularly in arrangements where there could be as many as ten to sixteen reflexions.

Nomarski then gave details of developments in laser techniques. It is now possible to produce a beam which is constant in intensity over an area approximately equal to that of a single cell, and dose reproducibility has been improved to about 10 per cent by surrounding the laser with a $0 \cdot 5-\mathrm{mm}$ thick water jacket. Tho available wavelengths may soon be extended by harmonic generation from two fundamental wave-lengths at $6940 \AA$ and $10600 \AA$ with the aid of a new crystal and, in the near future, repeatable pulses varying in length from $50 \mu$ sec to 6 msec at $0 \cdot 1$-see intervals may be available. Glubrecht suggested that when this became possible dose-rate effects would be very interesting, and drew an analogy with pulse radiolysis.

There was then a discussion on the importance of localization of the radiation delivered by a microbeam system, and Nomarski indicated that, for ultra-violet light, precision of the order of $0.15 \mu$ was possible for a thin target. P. P. Dendy (Cambridge) and A. Forer (Copenhagen) both supported the importance of precise physical location but drew attention to biological difficulties which include the unavoidable irradiation of membranes and other cell parts in addition to the target, and the ease with which biochemical changes can be transferred from the site of the primary lesion.

M. Ernst (Hannover) described a recently constructed $\mathrm{X}$-ray microbeam which uses 5 -keV $\mathrm{X}$-rays to irradiate an area approximately $4 \cdot 5 \mu$ in diameter. The whole apparatus is contained in a constant-temperature box which can be sterilized. In this way, uncovered biological specimens can be used, and this, in turn, allows the use of lowervoltage $\mathrm{X}$-rays which give a better localization of energy. The apparatus was compared with the earlier models of Seidel and Buchholtz ${ }^{1}$ and Seed ${ }^{2}$.

A discussion on the production of small holes followed and Nomarski indicated that $1 \mu$-diameter holes in $10 \mu$ thick tungsten could be produced by laser radiation. H. Mel (Paris) told the meeting about a relatively new procedure in which small areas of a surface can be weakened by the deposition of certain elements followed by neutron irradiation. Suitable chemical treatment leads to the production of very small regularly shaped holes at tho weakened sites.

Smith gave a brief outline of a new electron microbeam which is being built in Cambridge. It is hoped ultimately to obtain a $3 \mu$ spot of $50-\mathrm{keV}$ electrons, and incident illumination coupled with phase contrast will be used to view the biological material and control the site of irradiation.

The session ended with a description by Forer of a modified reflecting objective which permits the observation of a cell in polarized light under phase contrast conditions during ultra-violet microbeam irradiation. Nomarski pointed out the advantage of circularly polarized light for this type of work, particularly at high numerical apertures.

In the second session, the results of some recent experiments were presented. Prof. H. Glubrecht (Hannover) took the chair and suggested that the speakers should try to show how their experiments had extended ancillary techniques and quantitative methods for assaying the biological effect, both of which are strictly limited in microbeam work. Bessis described some work in which mitochondria in $K B$ cells had been stained with various vital stains. At staining concentrations which were twenty times lower than the limit of visibility, mitochondria became highly sensitive to laser microbeam irradiations. An electron microscope study of the irradiated cell showed that mitochondria which had been hit, were extensively damaged. Certain mitochondria which were not in the irradiated region showed structural changes $2-3 \mathrm{~h}$ after irradiation but they had recovered by $24 \mathrm{~h}$.

A discussion followed on valid criteria for deciding if a cell is alive, and Bessis stated that, in their work, the ability to take up nucleic acid precursors and the activity of enzymes had been used as eriteria. This point was taken up by the next speaker when Dendy discussed some experiments which had been performed at Cambridge. He referred briefly to earlier micro-irradiation 
experiments in which effects had only been investigated for a fow hours and it had been realized that an important factor in the cell viability problem was the ability or otherwise of irradiated cells to develop into colonies. The most recent experiments had therefore been designed to study the development of single cells for 7 days after irradiation with a microbeam of heterochromatic ultraviolet light. At the end of this time, several irradiated cells had formed small colonies which contained a number of morphologically normal cells. A study of the DNA metabolism of individual cells in these colonies at 7 days showed many anomalies, even in the morphologically normal cells.

Forer gave a brief account of the use of polarizing microscopy coupled with ultra-violet microbeam irradia- tion to study the effects on chromosome separation when a small volume of the spindle fibres is irradiated, and Glubrecht presented some results which were obtained when moss cells were irradiated with a monochromatic ultra-violet microbeam. In the latter experiments, cell killing was most efficient when $\mathrm{I}$ s giation at $\lambda=2650 \AA$ was directed at the nucleus but $\lambda=2800 \AA$ was most efficient when directed at the eytoplasm.

The meeting ended with a tour of the new Laboratoire de Pathologie Cellulairo, and the Chairman thanked Prof. Bessis for making all the arrangements for the meoting and thanked the representative of NATO, Ing. Gen. Giboin, for financial support. P. P. DENDY

Seidel, F., and Buchholtz, C., Naturwissenschaften, 47, 360 (1960). ${ }^{2}$ Sced, J., Proc. Roy. Soc., B, 152, 387 (1960).

\section{IODINE-LABELLED PROTEINS AND HORMONES}

$\mathrm{E}$ NCOURAGED by the success of a symposium in 1964 on the preparation and biomedical application of labelled molecules Euratom has sponsored another more specialized meeting on problems connected with the preparation and use of labelled proteins. This was held at the University of Pisa in January 1966 and attracted some 150 participants. As might be anticipated from a survey of the literature, nearly all the communications were concerned with proteins labelled with iodine isotopes, the 3 -day conference being broadly equally divided into sessions on hormones and non-hormonal plasma proteins.

Hughes (Boston) reviewed the chemistry of iodination and the particular chemical requirements for satisfactory trace-labelling of proteins. For most purposes the protein should retain its biological activity after labelling. He considered that iodotyrosines might conceivably be used in vivo for protein synthesis but the opportunity seldom presented for this to happen because of the widespread distribution and rapidity of action of tissue deiodinases. Rosa (Saluggia) emphasized the importance of achieving a truly random distribution of isotopic iodine throughout the population of protein molecules and produced further details of the electrolytic method of doing this which he has elaborated in collaboration with Donato and his group at Pisa. It remained for Freeman (London) to discuss biological methods of verifying that the labelled protein is a reliable tracer since it is generally accepted that only in vivo tests are sufficiently sensitive. He mainly favoured measurements of retention in the livers of rats, of catabolic rates in rabbits (if necessary rendered tolerant to human proteins), and of iodide activities in the urine and body water in the first $24 \mathrm{~h}$ in man. These and other speakers emphasized the crucial importance of using only proteins which have been circumspectly handled before labelling, and of taking steps afterwards to minimize self-irradiation damage.

In introducing a session on metabolic studies with labelled plasma proteins McFarlane (London) recom. mended that speakers should refer specifically to absolute or fractional rates of turnover as the case might be. Since iodine isotopes are not used for protein synthesis, conelusions about synthesis can only be derived indirectly from slopes of plasma specific activity curves of animals in metabolic equilibrium. These are proportional to fractions of the total body pool synthesized in unit time whereas currently used procedures for measuring catabolic rates give them as fractions of the plasma pool. It was important therefore also to specify the pool. Bianchi (Pisa) and Sorin reviewed the use of iodine-labelled albumin in metabolie studies, Andersen (Copenhagen) did the same for $\gamma$-globulin and Regoeczi (London) for fibrinogen. These were mainly straightforward communications, but controversial questions arose when subsequent speakers discussed mechanisms for regulating plasma protein turnover. Rothschild (New York) reported results of experiments in which low albumin concentrations were produced in rabbits by infusing $\gamma$-globulin or dextran and in which little or no change was observed in the mass of albumin catabolized per day. Fractional synthesis rates in these experiments were unrelated to fractional or absolute catabolic rates, to albumin pool sizes or to concentrations and in fact were sub-normal. This apparent paradox could be resolved by postulating a control mechanism based on the colloid osmotic pressure of hepatic interstitial albumin which is assumed to be increased by injections of $\gamma$-globulin or dextran. Dykes (Birmingham), on the other hand, found greatly reduced absolute catabolic rates in cirrhotic patients with low albumin concentrations both of which were restored to normal by infusions of albumin. He visualized a second-order relationship between albumin concentration and absolute catabolic rate.

Included in a variety of shorter papers wero descriptions of the preparation and use of tritium-labelled plasma proteins by Gostonyi et al. (Budapest) and by Gerber et al. (Mol, Belgium). Gordon and Jacques (London) reported on the distribution of iodine-labelled proteins in subcellular particles of the rat liver. Høedt-Rasmussen (Copenhagen) reported on a 10-20 per cent extravaseular catabolism of parenterally administered albumin, and Milhaud (Paris) on the effects of ligaturing the thoracic duct on ${ }^{131} \mathrm{I}$-albumin distribution and metabolism in rats.

Most fittingly, a culminating session to this part of the conference consisted of a round-table discussion of mathematical methods of analysing results. Experts on the panel comprised Donato (Pisa), Matthews (London), Nosslin (Malmö), Segrò (Camerino), and Vitek (Prague). The more recently published methods of Nosslin, which are largely independent of compartmental considerations, received most attention. While Nosslin agreed that his second method, which is based on integrating areas under plasma and total body activity curves, might be less vulnerable to orrors associated with identifying terminal slopes of these curves, he considered it was not altogether free of them, and indeed that the accuracy of all methods was to some extent limited by this factor. The deconvolution method of Vitek and Donato was also the subject of some discussion, as was the use of analogue computers by Segrè.

In the sessions on hormone labelling it was soon apparent that a greater degree of protein modification is permissible and altogether higher specific activities are required. Some seventeen hormones can now be estimated by radioimmunoassay, and Yalow (New York) considered the 